\title{
A Water Loop Design for the CRAFT Project towards the Testing of CFETR Water-Cooled Blanket and Divertor
}

\author{
Xiaoman Cheng ${ }^{1}{ }^{(}$, Zihan Liu $^{2}$, Songlin Liu ${ }^{3, *}$, Changhong Peng ${ }^{2}$, Wenjia Wang ${ }^{2,3}$ and Qixin Ling ${ }^{2,3}$ \\ 1 Hefei Comprehensive National Science Center, Institute of Energy, Hefei 230000, China; cxm@ie.ah.cn \\ 2 School of Nuclear Science and Technology, University of Science and Technology of China, \\ Hefei 230026, China; zihanliu@mail.ustc.edu.cn (Z.L.); pengch@ustc.edu.cn (C.P.); \\ wangwenjia@ipp.ac.cn (W.W.); qixin.ling@ipp.ac.cn (Q.L.) \\ 3 Institute of Plasma Physics, Hefei Institutes of Physical Science, Chinese Academy of Sciences, \\ Hefei 230031, China \\ * Correspondence: slliu@ipp.ac.cn
}

check for updates

Citation: Cheng, X.; Liu, Z.; Liu, S.; Peng, C.; Wang, W.; Ling, Q. A Water Loop Design for the CRAFT Project towards the Testing of CFETR Water-Cooled Blanket and Divertor. Energies 2021, 14, 7354. https:// doi.org/10.3390/en14217354

Academic Editors: Dimitris Drikakis, Hiroshi Sekimoto and Dan Gabriel Cacuci

Received: 30 July 2021

Accepted: 2 November 2021

Published: 4 November 2021

Publisher's Note: MDPI stays neutral with regard to jurisdictional claims in published maps and institutional affiliations.

Copyright: (C) 2021 by the authors Licensee MDPI, Basel, Switzerland. This article is an open access article distributed under the terms and conditions of the Creative Commons Attribution (CC BY) license (https:// creativecommons.org/licenses/by/ $4.0 /)$.

\begin{abstract}
As one of the tasks of the Comprehensive Research Facility for Fusion Technology (CRAFT), a High Heat Flux (HHF) testing device will be built to test the blanket and divertor of Chinese Fusion Engineering Testing Reactor (CFETR). The water loop is a key system of the HHF testing device. The main objective of the water loop is to provide deionized water at specific temperature, pressure, and flow rate for different testing experiments of the water-cooled blanket and water-cooled divertor components. The design of the water loop has been through three major steps. Firstly, the water cooled blanket and divertor were designed and analyzed, in detail, for CFETR. Secondly, thermal hydraulic features of the prototypes were abstracted from the analyses results. Then, the experiment plan was made so that the preliminary design of the water loop was carried out. The third step was the engineering design, which was conducted through cooperation with an industrial enterprise with certifications. At present, the water loop is ready for fabrication and construction. The water loop will be completed, for commissioning operation, by August 2022, as scheduled. After that, the experiments will be carried out step by step and provide solid technical base to CFETR.
\end{abstract}

Keywords: CFETR; CRAFT; blanket and divertor; experiment plan; water loop design

\section{Introduction}

Fusion energy is an environment-friendly new energy, which is a promising way to solve the increasingly serious energy crisis and global warming. According to the roadmap for Chinese magnetic confinement fusion development, China will independently design and build the Chinese Fusion Engineering Testing Reactor (CFETR). The goal of CFETR is to achieve stable operation, tritium self-sufficiency, and, finally, to realize commercial operation and power generation [1].

Blanket and divertor are two crucial components in CFETR and future fusion DEMO. The main functions of the blanket are to realize tritium self-sufficiency, convert fusion energy for electricity production, and provide shielding. The divertor is used for removing the impurities and helium ashes in the plasma. Besides, the divertor needs to resist extremely high heat flux from the plasma. For CFETR, the blanket and the divertor both have water-cooled [2,3] and helium-cooled concepts [4,5]. Experiments are indispensable to verify and validate the design and performance of the blanket and divertor.

Comprehensive Research Facility for Fusion Technology (CRAFT) is one of the national big science and technology facilities in China. Its objectives are to explore and master crucial technologies of key components and systems, to establish standards of manufacture, to build key prototype systems, and to validate the technologies for the successful construction of CFETR. The construction of CRAFT started on 20 September 2019 in Hefei, Anhui 
Province, and it will last for 5 years and 8 months with joint funds from central and local governments.

CRAFT consists of 20 different facilities that address most of the key technologies and systems of CFETR. Thereinto, a High Heat Flux (HHF) testing facility will be built to test the blanket and divertor of CFETR. This test device is equipped with two Electron Beam Guns (EBGs), water loop, helium loop, and vacuum chamber. It is constructed to:

- provide a testing environment of high thermal radiation loads, thermal hydraulics for water-cooled and helium-cooled divertor, and blanket of CFETR;

- test prototype components to verify their heat-resisting and thermal hydraulic performances;

- evaluate the manufacturing technologies to determine the standards and criteria for design and manufacture.

The main objective of the water loop is to provide deionized water at specific temperature, pressure and flow rate for testing water-cooled blanket, and water-cooled divertor components towards CFETR. Based on the design and analyses of the CFETR prototype, the main parameters and functions of the water loop were determined. In favor of the experiment performance, the water loop consists of high pressure water loop and low pressure water loop. The operation condition of the high pressure water loop is $4 \sim 16.5 \mathrm{MPa} / 70 \sim 340{ }^{\circ} \mathrm{C}$. The low pressure water loop is capable of two-phase flow experiments under atmospheric pressure.

In this paper, Section 2 introduces the design features and analyses results of the CFETR water-cooled blanket and divertor. Based on that, the experiment plan is introduced in Section 3. Then, the water loop design is indicated in Sections 4 and 5. At last, is the discussion and conclusion.

\section{Water Cooled Blanket and Water-Cooled Divertor of CFETR}

The engineering design of CFETR started in December 2017. Last year, the watercooled blanket and water-cooled divertor basically completed the design. The water-cooled blanket uses the design scheme of multi-module segment [2]. The water coolant operates under the pressure of $15.5 \mathrm{MPa}$, and the inlet/outlet temperature of the blanket module is $285^{\circ} \mathrm{C} / 325^{\circ} \mathrm{C}$. Square channels with a cross section of $8 \times 8 \mathrm{~mm}^{2}$ are embedded in the First Wall (FW) in which the coolant flows along the radial-toroidal-radial direction. The breeding zones are filled with a mixed pebble bed of $\mathrm{Li}_{2} \mathrm{TiO}_{3}$ and $\mathrm{Be}_{12} \mathrm{Ti}$, which is cooled by the cooling tubes with multiple bends. The water-cooled blanket is able to withstand steady state heat flux of $0.5 \mathrm{MW} / \mathrm{m}^{2}$ and transient heat flux of $1 \mathrm{MW} / \mathrm{m}^{2}[6,7]$. As for the divertor, the maximum inlet pressure of water coolant is $5 \mathrm{MPa}$. Inlet temperature is $140^{\circ} \mathrm{C}$, and the temperature rise is below $40{ }^{\circ} \mathrm{C}$ [8]. From the perspective of thermal hydraulics, the divertor is required to resist steady state heat flux of $10 \mathrm{MW} / \mathrm{m}^{2}$ and transient heat flux of $20 \mathrm{MW} / \mathrm{m}^{2}$. The prototype of the water-cooled blanket and the water-cooled divertor for CFETR is shown in Figure 1. Although the water-cooled blanket and the water-cooled divertor are different in functions, they still have some common grounds:

- facing one-side high heat flux

- using high pressure and high temperature water coolant

- having complex coolant channels

- $\quad$ operating in high vacuum environment

The operation events of CFETR can be classified into five categories referring to ITER, as shown in Table 1 [9]. Events in Category I and II are taken into account for the test condition of water coolant due to the high frequency. Besides, the capability and safety of the experimental water loop should also be considered. In Category I, the plasma pulse operation is defined as normal operating condition due to the pulsed nature of fusion plasma so far. As for Category II, the event description still refers to ITER for lack of detailed frequency data sources for CFETR [10]. The events of the blanket and divertor system in Category II are listed in Table 2. 


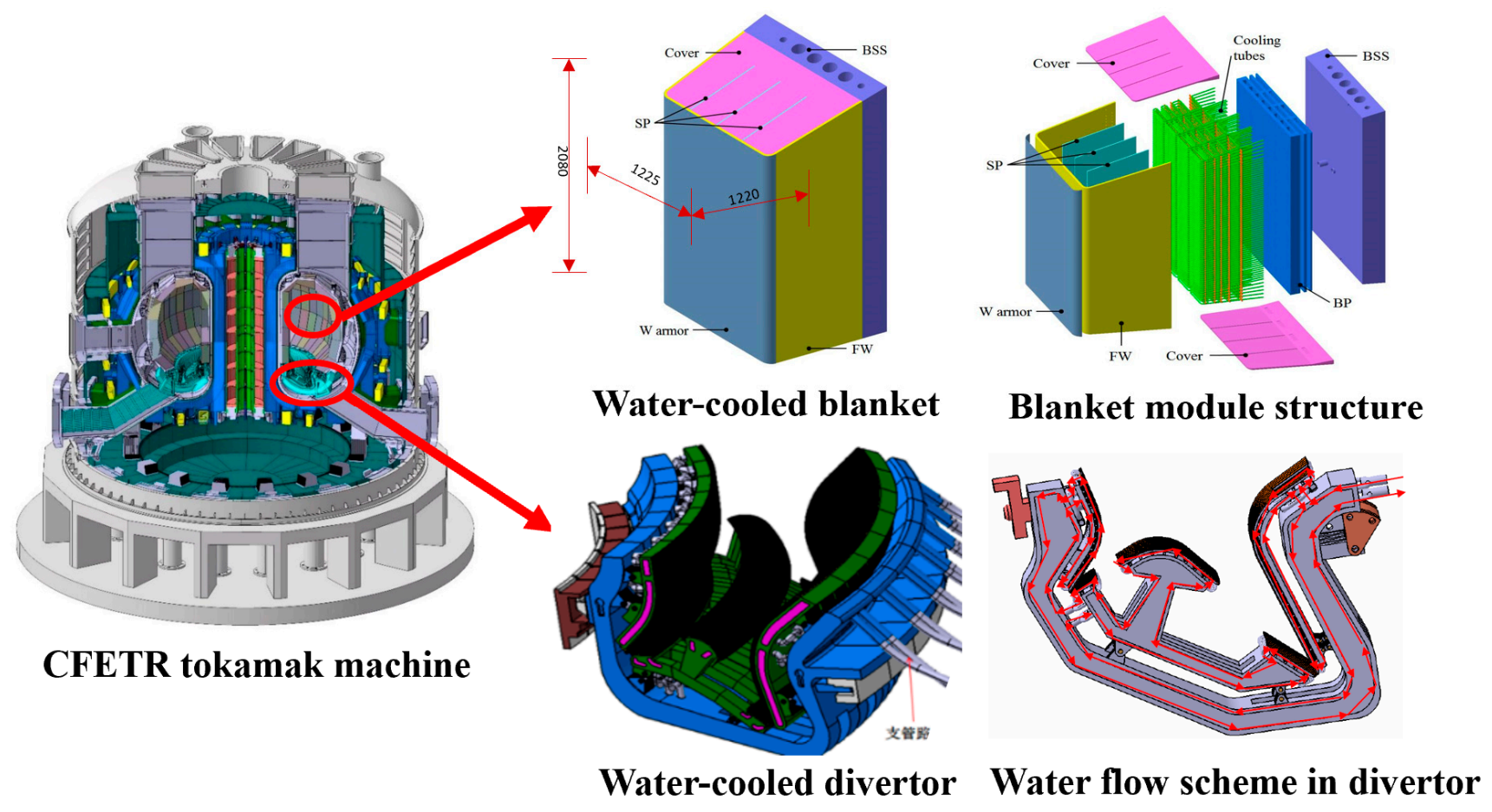

Figure 1. Water-cooled blanket and water-cooled divertor of CFETR.

Table 1. Event categories of CFETR.

\begin{tabular}{ccc}
\hline Category & Event Frequency/yr & CFETR Plant Condition \\
\hline I & $>1$ & Normal operation \\
II & $10^{-2}-1$ & Incident \\
III & $10^{-4}-10^{-2}$ & Accident \\
IV & $10^{-6}-10^{-4}$ & Hypothetical \\
V & $<10^{-6}$ & \\
\hline
\end{tabular}

Table 2. Events in Category II for the blanket and divertor system.

\begin{tabular}{cr}
\hline No. & Description of Event \\
\hline 1 & Loss of flow in a blanket coolant circuit due to pump trip \\
2 & Loss of flow in a blanket coolant channel \\
3 & Ex-vessel coolant leakage due to small rupture of blanket \\
4 & coolant circuit pipe inside TCWS ${ }^{1}$ vault \\
5 & Small blanket in-vessel coolant leakage-equivalent break size: a few cm ${ }^{2}$ \\
6 & Loss of flow in a divertor coolant circuit due to pump trip \\
\hline TCWS $^{1}:$ Tokamak Cooling Water System.
\end{tabular}

Those selected events were analyzed to obtain the enveloping test condition for the water loop. Moreover, key phenomena were captured, and will be validated, in experiments. For normal operation in Category I, the thermal hydraulic parameters of the coolant also have pulsed characteristics due to pulsed heating loads. Taking the base case of the blanket system as an example [6], the pressure range is 15.38-16.0 MPa, and the inlet temperature range is $273-285^{\circ} \mathrm{C}$ during the pulse operation. The two-phase flow does not occur during the whole process.

In category II, the ex-vessel small rupture of the blanket coolant circuit pipe is explained as an example. The RELAP5 model can be found in a previous report [11]. Main results are shown in Figure 2. In this case, no mitigation method is applied. Therefore, the 
coolant continues to leak until all the coolant runs out. Then, the coolant pressure declines continuously. As the decay heat decreases with time, after plasma shutdown, the coolant temperature decreases too. However, the two-phase flow occurs for lack of cooling. Due to the parallel structure of blanket modules and sectors, the flow instability is observed. From the results, it is clear that the thermal hydraulic parameters of the coolant can decrease to a much lower level, even without human intervention, at $1000 \mathrm{~s}$ after the event. Therefore, we pay more attention to the period of 0-1000 s. During this period, the pressure is in the range of $8-15.5 \mathrm{MPa}$, and the temperature is in the range of $292-325^{\circ} \mathrm{C}$. The maximum void fraction is 0.68 .
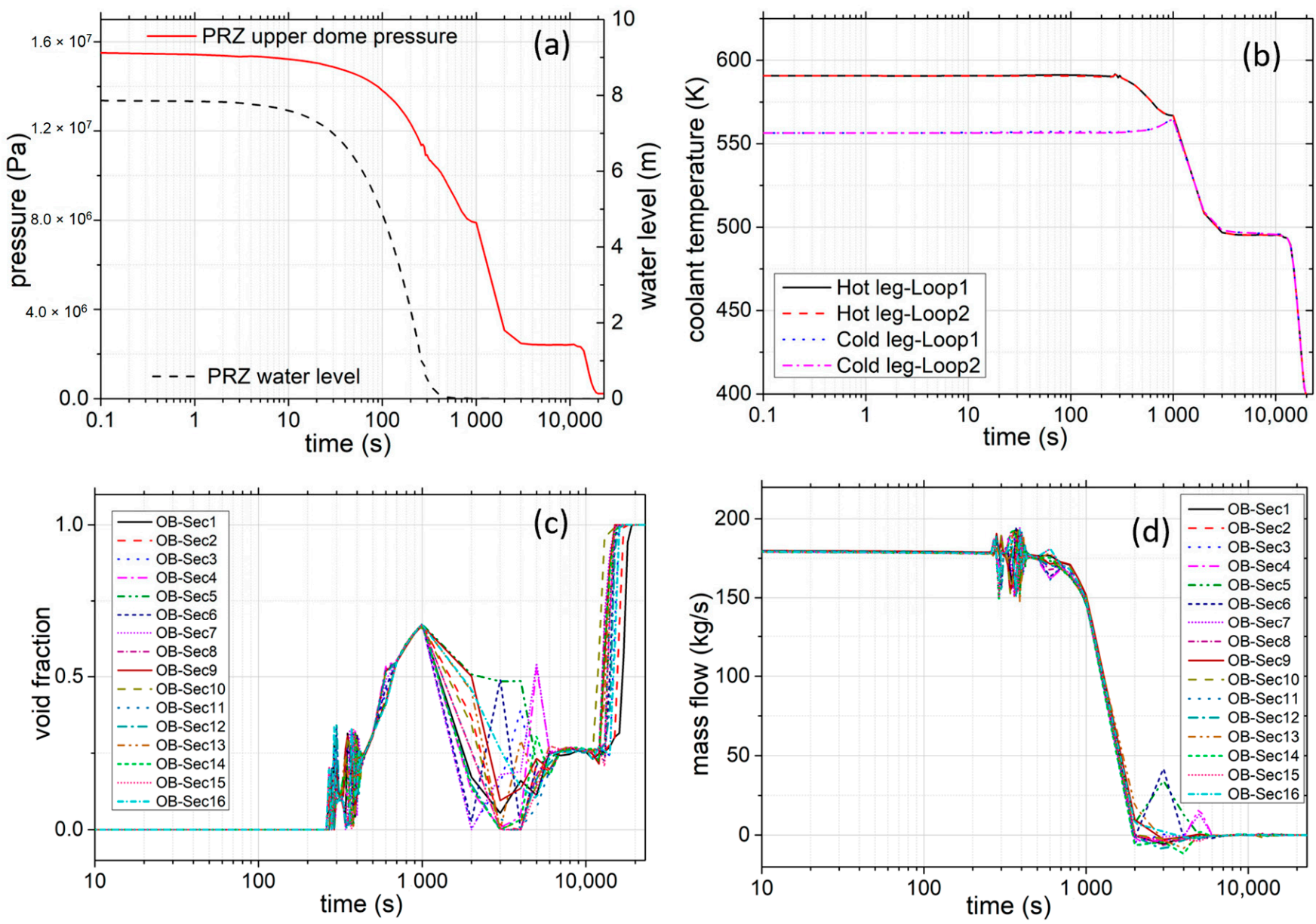

Figure 2. Ex-vessel small rupture of water-cooled blanket coolant circuit pipe: (a) pressurizer pressure and water level; (b) coolant temperature; (c) void fraction of coolant; (d) mass flow of coolant.

It should be noted that all events herein are caused by single fault, and only the most serious period of each event is considered. For the water-cooled divertor, most attention is focused on the manufacturing technology and the heat-resisting capability for one-side high heat flux. Besides, the operating temperature and pressure of the water-cooled divertor is below that of the water-cooled blanket $[3,8]$. Therefore, the operation condition of the water-cooled blanket is considered as enveloping test condition. According to the analyses of events in Category I and II $[6,11,12]$, it can be concluded that:

- the mass flow is $40-110 \%$ of the steady state level;

- the temperature is in the range of $70-180^{\circ} \mathrm{C}$ for divertor and $227-337{ }^{\circ} \mathrm{C}$ for blanket;

- the pressure is in the range of 4.0-5.0 MPa for divertor and 8.0-16.5 MPa for blanket;

- the maximum void fraction is $68 \%$. 


\section{Experiment Plan}

The experiment plan for the water loop of CRAFT was made according to the design and analyses results of the water-cooled blanket and divertor of CFETR. Primary experiments are introduced below.

\subsection{Experiment of Critical Heat Flux}

The FW of the blanket faces the one-side heat flux from plasma. The average steady state heat flux is assumed to be $0.5 \mathrm{MW} / \mathrm{m}^{2}$. However, the heat flux might be uneven and much higher at certain positions $[13,14]$, which may damage the structures. At the same time, there is nuclear heat induced by fast neutrons. To remove the heat, 95 channels, with the cross section of $8 \times 8 \mathrm{~mm}^{2}$, are embedded in the FW. Every two channels are set up as one group and flows in the opposite direction. The purposes of this experiment are to:

- verify the heat removal capability of the FW;

- obtain the Critical Heat Flux (CHF) to prevent burn up of the FW.

There are 4 parallel channels abstracted as typical experiment units, namely 2 groups of square channels with opposite flow directions. The schematic view of the test section is shown in Figure 3. The manifolds and inlet/outlet channels provide similar fullydeveloped flow conditions. Since the nuclear heat of the manifold and inlet/outlet channel occupies only $\sim 6 \%$ of the FW total heat load, only the plasma facing section is going to be heated in the experiment $[15,16]$. Specifically, the heated section will be heated by two separate Direct-Current (DC) power supplies, which represent the nuclear heat and the heat flux, respectively. The maximum heat flux required is $\sim 5 \mathrm{MW} / \mathrm{m}^{2}$. Inconel 625 is selected as the structural material to facilitate the DC heating. The flow area remains $8 \times 8 \mathrm{~mm}^{2}$ in each channel, and the flow path keeps the same as the prototype. Since the nuclear heat decreases along the radial direction, the heated Inconel structure needs equivalent cross section design to reproduce that feature [17]. The detailed structure design of the test section is under development.

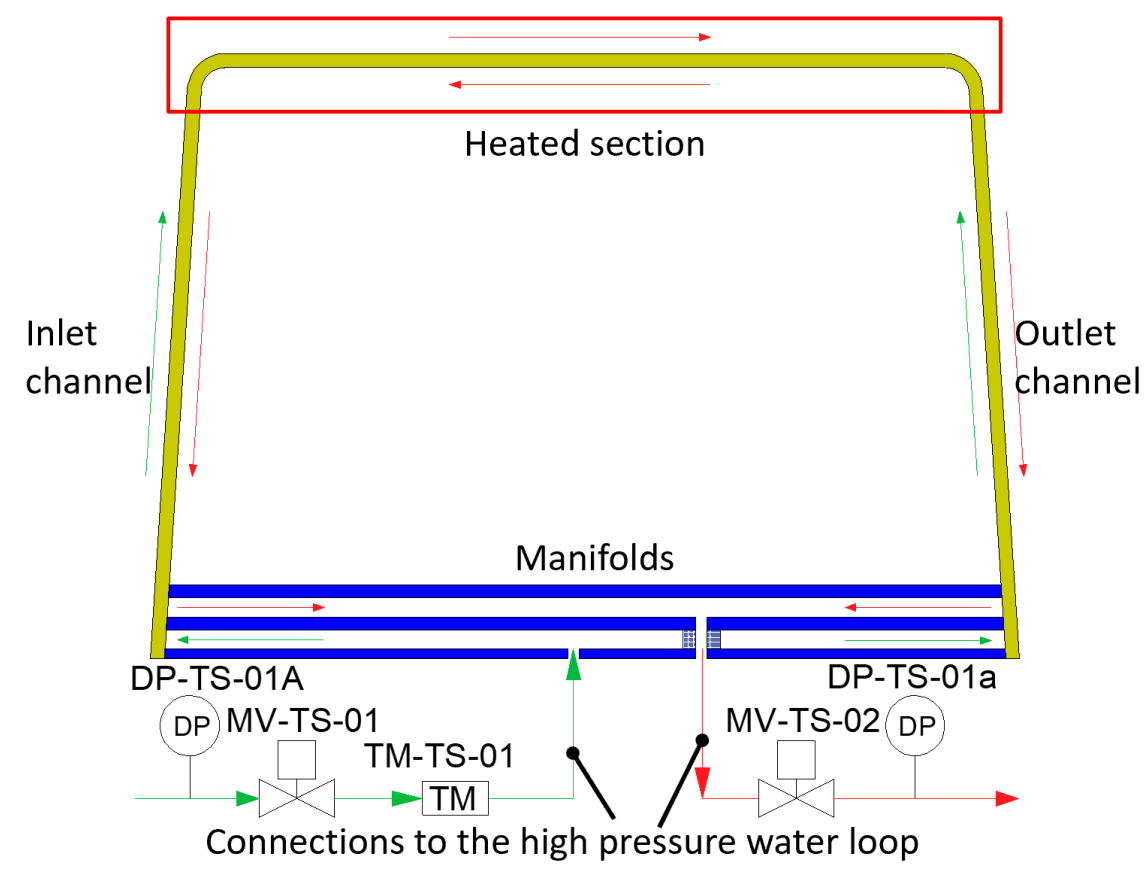

Figure 3. Schematic view of the CHF test section. 


\subsection{Experiment of One-Side Thermal Radiation by EBGs}

The water-cooled blanket and divertor will use Reduced Activated Ferritic Martensitic (RAFM) steel. Tungsten is coated on the plasma facing side. In this experiment, the test sections will use the exact same structure and material with the prototype. The test section will be put into the vacuum chamber, and the two EBGs will be employed to generate one-side steady state and transient heat flux [18], as shown in Figure 4. The purposes of this experiment are to:

- $\quad$ verify the steady state and transient heat-resisting capability of the water-cooled blanket and divertor;

- verify the material performance and manufacturing techniques.

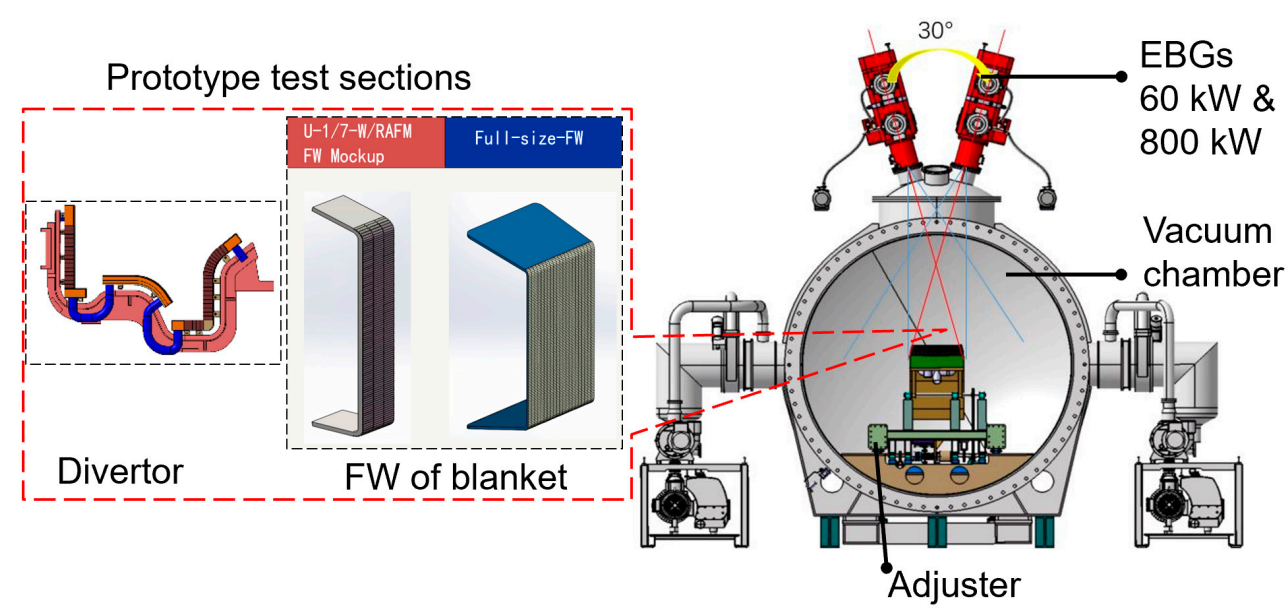

Figure 4. Schematic view of the one-side thermal radiation by EBGs.

\subsection{Experiment of Flow Instability}

The blanket system has many parallel structures. Specifically, the 95 channels in the FW of one blanket module, the 27 blanket modules in one blanket sector, and 16 blanket sectors in the tokamak machine are all in parallel from different levels. Uneven heat flux or hot spots may result in two-phase flow in the FW. Besides, two-phase flow may also appear in the coolant system during abnormal operation events, such as small rupture of cooling circuit pipes. Then, the flow instability may occur [19], which will damage the system and is not expected to happen. Therefore, the purposes of this experiment are to:

- clarify the mechanism of flow instability from different parallel levels;

- obtain the critical void fraction for flow instability to occur and prevent damage of the system.

Flow instability between different blanket modules in one sub-sector will use equivalent modules in the experiment. Each equivalent module shall keep the structure characteristics, including inclination, altitude, and heat source distribution, as shown in Figure 5. Detailed structure design of the test section is ongoing.

\subsection{Experiment of Flow Distribution}

As mentioned in Section 3.3, the blanket system has many parallel structures from different levels. The visualization of the flow distribution, among parallel channels/modules/ sectors, is going to be carried out under atmospheric pressure and temperature for the safety concern in the experiment. The test section will use Acrylic in favor of observation. The air will be used as the gas phase instead of steam. Apart from the flow distribution, many other important phenomena can also be observed through this experiment, including the void fraction distribution, the two-phase flow pattern, the pressure drop etc. The detailed structure design of the test section is underway. 


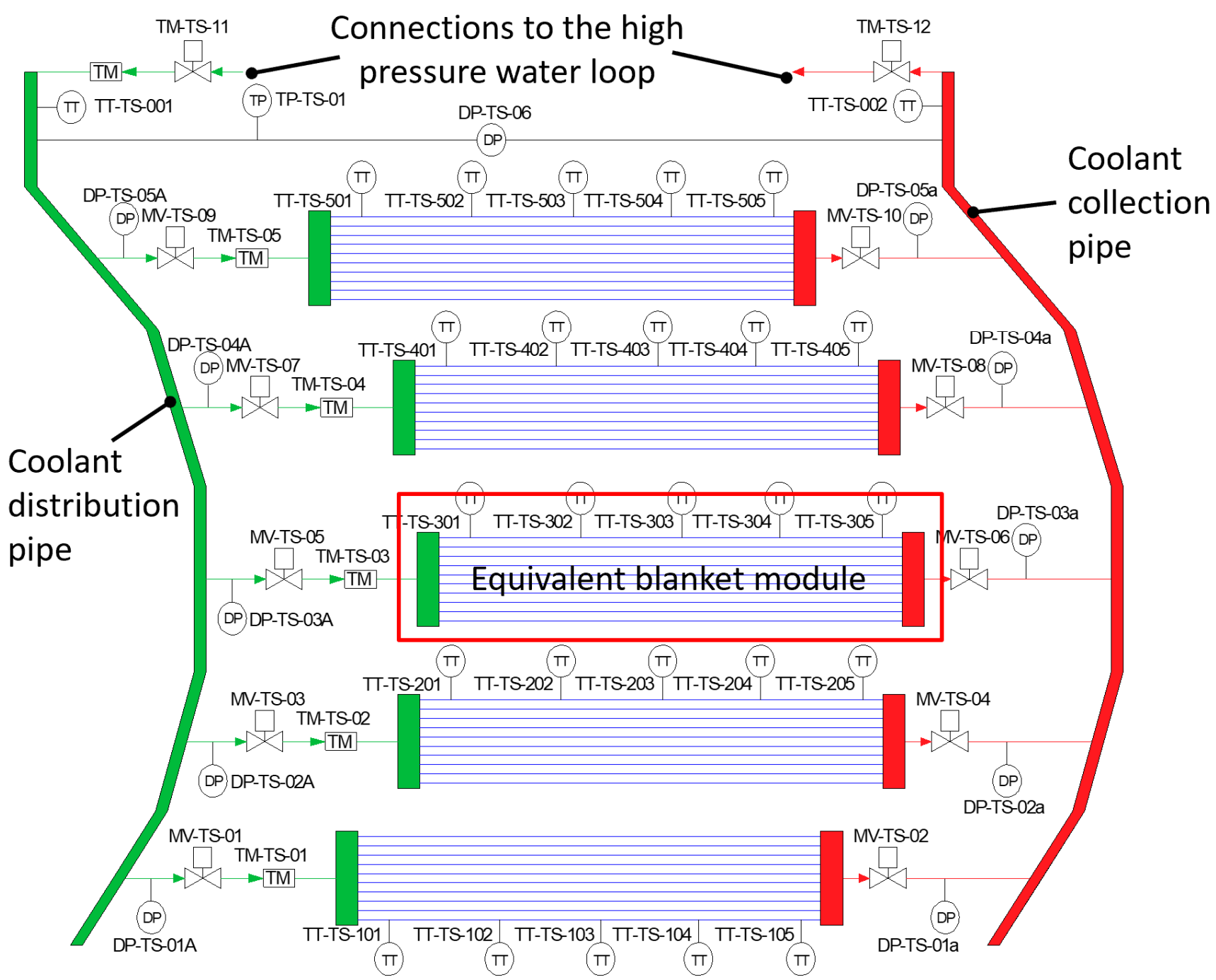

Figure 5. Schematic view of the flow instability test section.

\section{Water Loop Design}

The functions and main parameters of the water loop are determined based on the operating condition of each experiment. The water loop mainly consists of four subsystems, namely the high pressure water loop, the low pressure water loop, the component cooling water system, and the water charging system.

\subsection{High Pressure Water Loop}

The function of the high pressure water loop is to support high pressure experiments in Sections 3.1-3.3, while keeping stable operation. The high pressure water loop is composed of high temperature and high pressure canned pump, electric heating pressurizer (PZR), preheater, test section, high pressure mixer, 1\# heat exchanger (HX), 2\# HX, flow meters, control valves, related pipelines, and valve components. Besides, there is a discharge tank related to the PZR. The main function of the discharge tank is to collect water and steam, discharged through the Pressure Safety Valve (PSV) of the PZR and the test section. The scheme of the high pressure water loop is shown in Figure 6.

During the normal operation of the high pressure water loop, the canned pump provides a stable flow rate. Then, the deionized water enters the preheater after passing through the control valve and flow meter. After that, the water is heated further in the test section. The high temperature liquid, or two-phase flow at the outlet of the test section, is 
mixed with the lower temperature fluid from the bypass. Subsequently, the water is cooled by the $1 \# \mathrm{HX}$ or the $2 \# \mathrm{HX}$ and finally returns to the inlet of the canned pump.

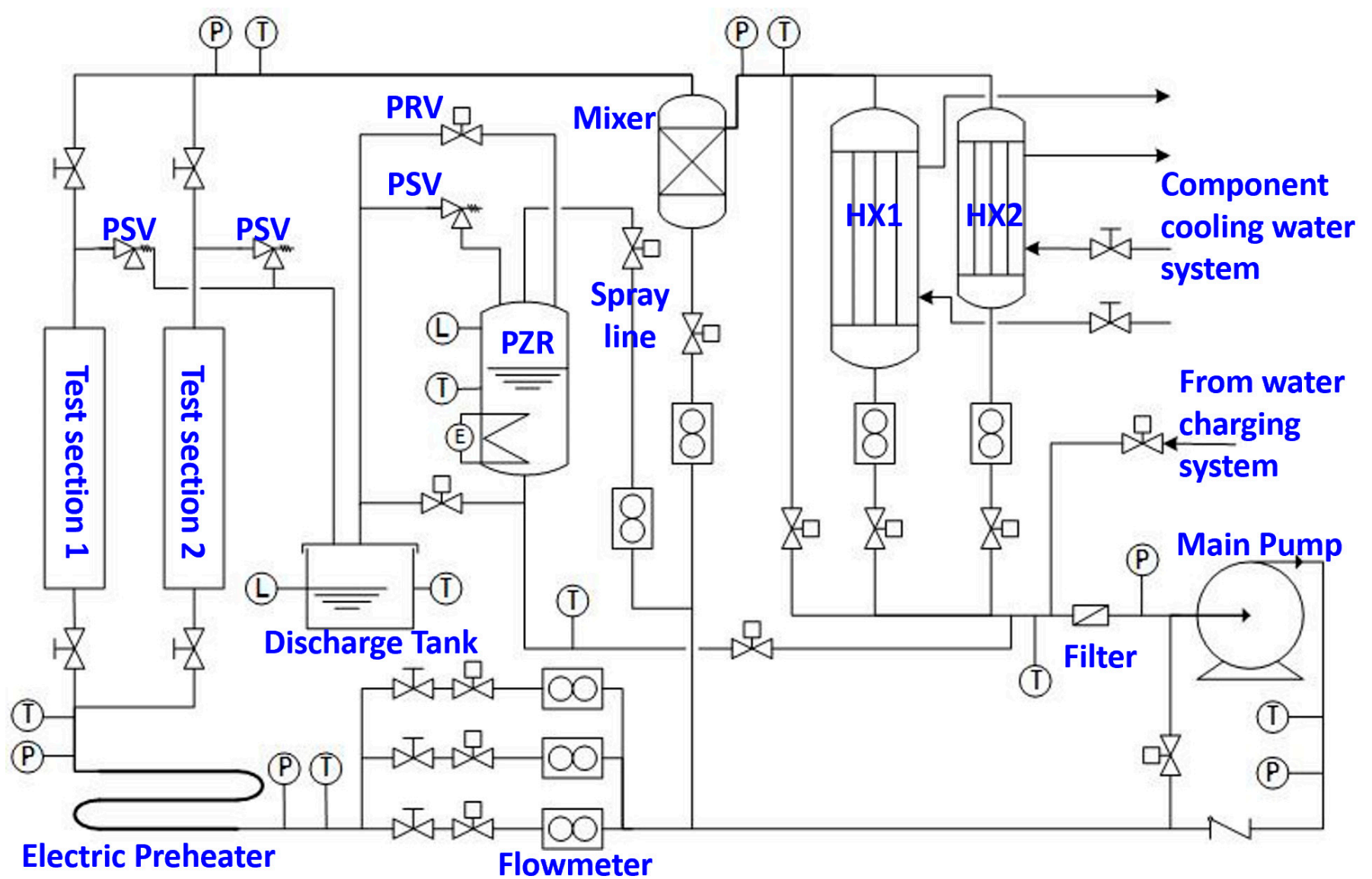

Figure 6. Scheme of the high pressure water loop.

The PZR surge line is connected to the canned pump inlet pipe for the pressure stability. The internal pressure of the PZR can be set manually, so the inlet pressure of the canned pump can be stabilized at any value between $3.5 \mathrm{MPa}$ and $16.5 \mathrm{MPa}$, according to experiment requirements. The pressure control method refers to that of the primary heat transfer system of the water-cooled blanket [11]. Three sets of control valve and flow meters are arranged in front of the preheater, which can accurately adjust the inlet flow of the test section. Only one set is put into service at each experiment condition. The power of the preheater can be adjusted precisely to ensure that the inlet temperature of the test section is stable at the set value. The use of the mixer is to prevent the two-phase flow at the outlet of the test section from directly entering the HXs and causing damage. Thus, 1\# HX and 2\# HX are in parallel. When the total heating power of the test section and the preheater is less than $400 \mathrm{~kW}$, the 2\# HX is used for heat transfer. When the total heating power of the test section and the preheater is higher than $400 \mathrm{~kW}$, the $1 \# \mathrm{HX}$ is used. The HX power can be adjusted by regulating the control valves at the outlets of the two HXs and the control valve on the bypass of the HXs to maintain the stability of the inlet temperature of the canned pump. Main design parameters of the high pressure water loop are listed in Table 3.

\subsection{Low Pressure Water Loop}

The low pressure water loop consists of three parts, namely the air supply line, the water supply line, and the air-water mixing and separation line as shown in Figure 7. The air supply line mainly includes air compression, air tank, Pressure Reducing Valve (PRV), air flow meters, control valves, as well as related pipelines and valves. The main function 
of the air supply line is to provide air with stable pressure and adjustable flow rate for the low pressure mixer. At the same time, the compressed air stored in the air tank is used as the driving air source of pneumatic valves at the inlets and outlets of the high pressure test sections for emergency isolation.

Table 3. Design parameters of the high pressure water loop.

\begin{tabular}{ccc}
\hline Item & Value & Unit \\
\hline Design pressure & 17.5 & $\mathrm{MPa}$ \\
Design temperature & 355 & ${ }^{\circ} \mathrm{C}$ \\
Volume of the PZR & 0.96 & $\mathrm{~m}^{3}$ \\
PZR electric heater power & 60 & $\mathrm{~kW}$ \\
1\# heat exchanger capacity & 2600 & $\mathrm{~kW}$ \\
2\# heat exchanger capacity & 415 & $\mathrm{~kW}$ \\
Flow rate of the main pump & 25 & $\mathrm{~m}^{3} / \mathrm{h}$ \\
Electric preheater power & 200 & $\mathrm{~kW}$ \\
Volume of discharge tank & 3.8 & $\mathrm{~m}^{3}$ \\
\hline
\end{tabular}

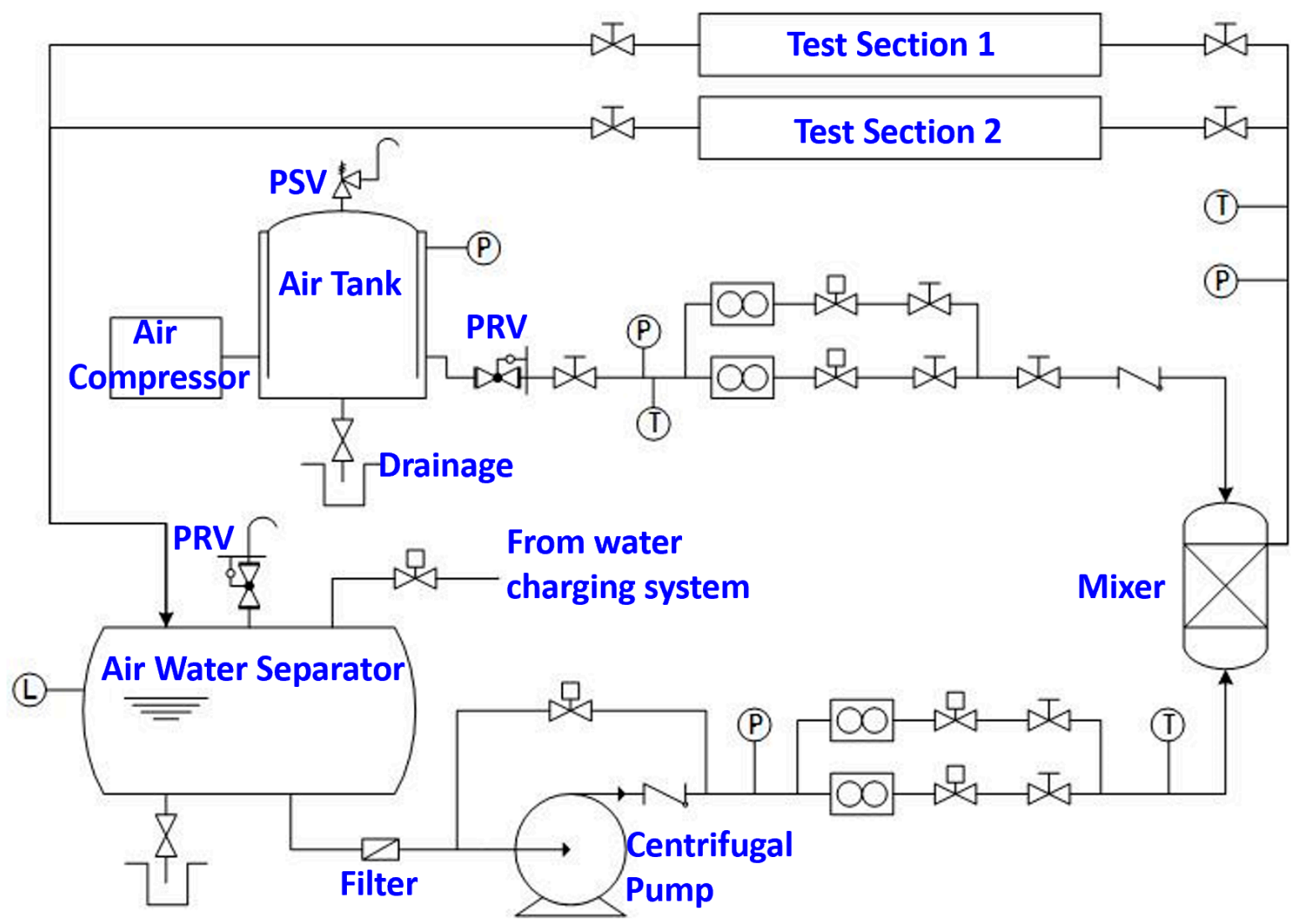

Figure 7. Scheme of the low pressure water loop.

The water supply line mainly includes the centrifugal pump, filters, water flow meters, control valves, related pipelines and valves. The main function of the water supply line is to provide water with stable pressure and adjustable flow rate for the low pressure mixer.

The air-water mixing and separation line is composed of low pressure mixer, air-water separator, test sections, related pipelines, and valves. The volume of the air-water separator is big enough and it is also used as the water tank for the centrifugal pump. The main function is to mix air and deionized water to provide a two-phase flow for the low-pressure test section, then separate air and water through the air-water separator, so the deionized water can be reused. Main parameters of the low pressure loop are listed in Table 4. 


\subsection{Component Cooling Water System}

The component cooling water system is composed of circulating cooling water pump, plate heat exchanger, cooling water tank, filter, related pipeline, and valves, as shown in Figure 8. The main function is to provide cooling water for 1\# HX, 2\# HX, canned pump, air compression, DC power supply and vacuum chamber with stable temperature and flow rate. Main parameters of the component cooling water system are listed in Table 5.

Table 4. Design parameters of the low pressure water loop.

\begin{tabular}{ccc}
\hline Item & Value & Unit \\
\hline Design pressure of air supply line & 1.0 & $\mathrm{MPa}$ \\
Design pressure of water supply line & 1.2 & $\mathrm{MPa}$ \\
Design temperature & 80 & ${ }^{\circ} \mathrm{C}$ \\
Flow rate of air compressor & $2-90$ & $\mathrm{~m}^{3} / \mathrm{h}$ \\
Flow rate of centrifugal pump & $10-160$ & $\mathrm{~m}^{3} / \mathrm{h}$ \\
Volume of air tank & 3.3 & $\mathrm{~m}^{3}$ \\
Volume of air water separator & 16.2 & $\mathrm{~m}^{3}$ \\
\hline
\end{tabular}

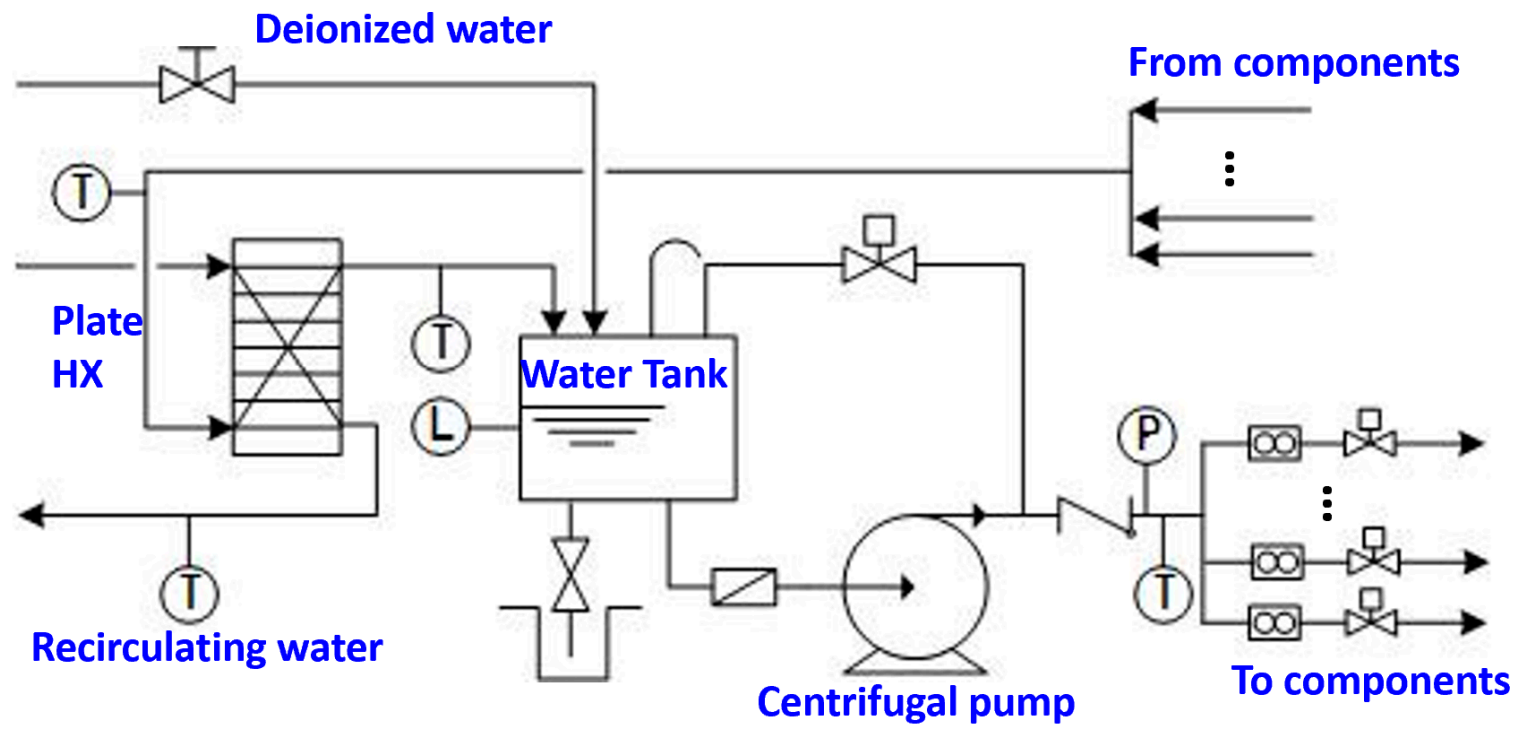

Figure 8. Scheme of the component cooling water system.

Table 5. Design parameters of the component cooling water system.

\begin{tabular}{ccc}
\hline Item & Value & Unit \\
\hline Design pressure & 0.8 & $\mathrm{MPa}$ \\
Design temperature & 80 & ${ }^{\circ} \mathrm{C}$ \\
Design flow rate & 280 & $\mathrm{~m}^{3} / \mathrm{h}$ \\
Cooling capacity & 3500 & $\mathrm{~kW}$ \\
\hline
\end{tabular}

\subsection{Water Charging System}

The water charging system mainly includes deionized water tank, plunger pump, metering pump, filter, related pipelines and valves as shown in Figure 9. The main function is to supply water for the high pressure water loop and the low pressure water loop using the plunger pump. Then, the metering pump is used for increasing the pressure of the high pressure water loop. The deionized water tank is equipped with an electric heater and a nitrogen sealing system, which can deoxygenate the water and prevent corrosion of the system pipelines and the test sections. Main parameters are listed in Table 6. 


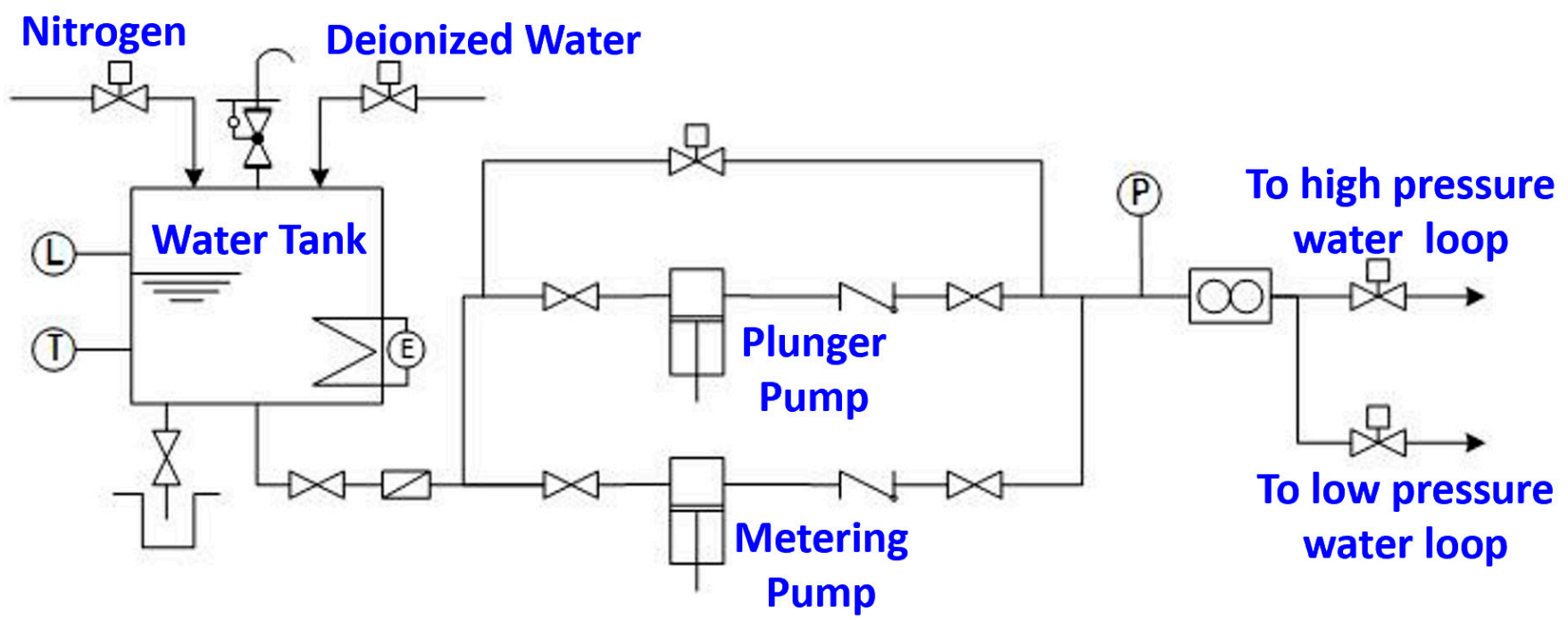

Figure 9. Scheme of the water charging system.

Table 6. Design parameters of the water charging system.

\begin{tabular}{ccc}
\hline Item & Value & Unit \\
\hline Outlet pressure of plunger pump & 6 & $\mathrm{MPa}$ \\
Flow rate of plunger pump & 5 & $\mathrm{~m}^{3} / \mathrm{h}$ \\
Outlet pressure of metering pump & 20 & $\mathrm{MPa}$ \\
Flow rate of metering pump & 0.4 & $\mathrm{~m}^{3} / \mathrm{h}$ \\
Volume of air tank & 2.4 & $\mathrm{~m}^{3}$ \\
\hline
\end{tabular}

\section{Layout of the Water Loop}

Based on the process design in Section 4, the engineering design of the water loop was completed by cooperation with an industrial enterprise with certifications. The 3D layout of the water loop in the CRAFT plant is shown in Figure 10. The water loop covers an area of $10 \times 12 \mathrm{~m}^{2}$. To accelerate the construction and ensure the quality, the water loop adopts modular design, consisting of 9 blocks. The 9 blocks can be fabricated at the same time in the factory so as to save time and reduce onsite assembling and inspection work. Block 1-4 are located on the first floor at the elevation of $0.0 \mathrm{~m}$. Block 5-8 are located on the second floor at the elevation of $+5.0 \mathrm{~m}$. Block 9 and the control cabinet are located on the third flow at the elevation of $+10.0 \mathrm{~m}$. Since the high pressure water loop and the low pressure loop are independent, they are arranged separately on different blocks. Block 1, 5, 7, and 9 belong to the high pressure water loop, which are located on the west side of the steel platform. Block 2 and 6 belong to the low pressure water loop, which are located at the south-east side of the steel platform. The other blocks are for auxiliary components. Except the test section for "experiment of one-side thermal radiation by EBGs" which will be put inside a vacuum chamber, test sections for other experiments will be connected to the water loop from the north side. On every block, there are respective instrument junction boxes and electrical junction boxes, so each block can realize independent functions. Then, the control signals are collected to the control cabinet through cable. After that, the signals are transmitted from the onsite cabinet to the control room though optical fiber. Main information of each block is summarized in Table 7. 


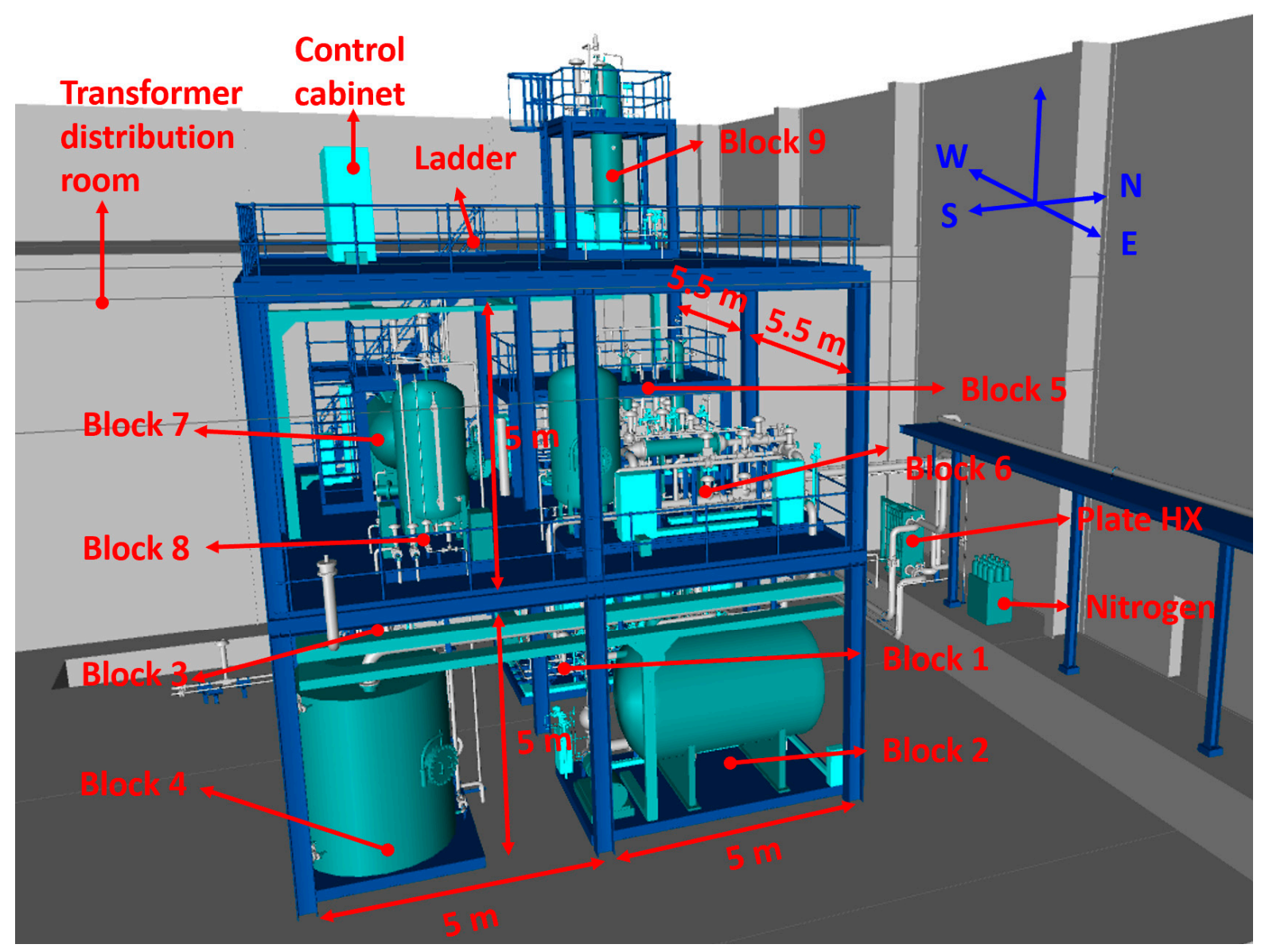

Figure 10. A 3D layout of the water loop in plant of CRAFT.

Table 7. Information of Block 1-9 of the water loop.

\begin{tabular}{|c|c|c|}
\hline No. & Components & Functions \\
\hline Block 1 & $\begin{array}{l}\text { Canned pump, preheater, high pressure } \\
\text { water flow meters and control valves }\end{array}$ & $\begin{array}{l}\text { High pressure water pumping, flow } \\
\text { control and measuring, preheating }\end{array}$ \\
\hline Block 2 & $\begin{array}{l}\text { Centrifugal pump of low pressure } \\
\text { water loop, air-water separator }\end{array}$ & $\begin{array}{l}\text { Air-water separating, low } \\
\text { pressure water pumping }\end{array}$ \\
\hline Block 3 & $\begin{array}{l}\text { Centrifugal pump of component cooling water system, plunger } \\
\text { pump and metering pump of water charging system }\end{array}$ & Water pumping \\
\hline Block 4 & Water tank of component cooling water system, air compressor & $\begin{array}{l}\text { Component cooling water } \\
\text { storage, air compressing }\end{array}$ \\
\hline Block 5 & High pressure mixer, 1\# HX, 2\# HX & Mixing, heat exchanging \\
\hline Block 6 & $\begin{array}{c}\text { Air tank, air flow meters and control valves, water flow meters } \\
\text { and control valves, low pressure mixer }\end{array}$ & Air and water supply and mixing \\
\hline Block 7 & Discharge tank & Water and steam discharge \\
\hline Block 8 & Water tank of water charging system, air dryer & Deionized water storage, air drying \\
\hline Block 9 & PZR & Pressure control \\
\hline
\end{tabular}

\section{Discussion and Conclusions}

With the financial support from the CRAFT project, a water loop will be constructed for testing the water-cooled blanket and water-cooled divertor components of CFETR in the frame of a HHF testing facility. This paper introduces the process of the water loop design. It started from the design and analyses of the water-cooled blanket and the water-cooled divertor prototypes of CFETR. Events in Category I and II were selected to obtain enveloping thermal hydraulic parameters for the water loop design. The experiment 
plan was set out by abstracting features of the prototypes from analyses results. Then, the function of the water loop was determined to fulfill experiment requirements. The conceptual design, preliminary design, and engineering design of the water loop were carried out step by step. Until now, the design of the water loop has been completed. The fabrication and construction of the water loop is about to start. According to the schedule, the water loop will be ready for commissioning by August 2022. The experiments will provide an important technical base for CFETR.

Author Contributions: Conceptualization, X.C. and Z.L.; methodology, S.L. and C.P.; software, X.C.; validation, W.W. and Q.L.; formal analysis, X.C. and Z.L.; investigation, X.C. and Z.L.; writing—original draft preparation, X.C.; writing—review and editing, S.L.; supervision, S.L. and C.P.; project administration, X.C. and S.L. All authors have read and agreed to the published version of the manuscript.

Funding: This work was funded by Comprehensive Research Facility for Fusion Technology Program of China under Contract No. 2018-000052-73-01-001228.

Data Availability Statement: Not applicable.

Acknowledgments: This work has been carried out in the framework of strategic cooperation of Institute of Energy with ASIPP and USTC. The project receives funding from the CRAFT program. The views and opinions expressed herein do not necessarily reflect those of ASIPP, USTC and the CRAFT program committee.

Conflicts of Interest: The authors declare no conflict of interest.

\section{References}

1. Li, J.; Ni, M.; Lu, Y. The frontier and perspective for tokamak development. Natl. Sci. Rev. 2019, 6, 382-383. [CrossRef]

2. Liu, S.; Cheng, X.; Ma, X.; Chen, L.; Jiang, K.; Xia, L.; Bao, H.; Wang, J.; Wang, W.; Peng, C.; et al. Progress on design and related R\&D activities for the water-cooled breeder blanket for CFETR. Theor. Appl. Mech. Lett. 2019, 9, 161-172.

3. Qin, S.; Yao, D.; Wang, Q.; Mao, X.; Liu, P.; Qian, X.; Xu, T.; Li, L.; Peng, X.; Lu, K.; et al. Preliminary design progress of the CFETR water-cooled divertor. IEEE Trans. Plasma Sci. 2020, 48, 1733-1742. [CrossRef]

4. Wang, X. Helium-cooled blanket design. In Proceedings of the CFETR Engineering Design Annual Conference, Langfang, China, 26-29 October 2020. (In Chinese)

5. Huang, W.; Lu, Y.; Zhang, L.; Liu, K.; Jin, Y.; Zheng, G.; Cai, L.; Zhu, Y.; Xue, M. Preliminary design and analysis of CFETR He-cooled divertor. Nucl. Fusion Plasma Phys. 2021, 41, 37-44. (In Chinese)

6. Cheng, X.; Ma, X.; Lu, P.; Wang, W.; Liu, S. Thermal dynamic analyses of the primary heat transfer system for the WCCB blanket of CFETR. Fusion Eng. Des. 2020, 161, 112067. [CrossRef]

7. Abdou, M.; Morley, N.B.; Smolentsev, S.; Ying, A.; Malang, S.; Rowcliffe, A.; Ulrickson, M. Blanket/first wall challenges and required R\&D on the pathway to DEMO. Fusion Eng. Des. 2015, 100, 2-43.

8. Yao, D. Water-cooled divertor design. In Proceedings of the CFETR Engineering Design Annual Conference, Langfang, China, 26-29 October 2020. (In Chinese)

9. Taylor, N. Accident Analysis Guidelines 4. IDM No. ITER_D_24TDZ8 v2.4. Available online: https://www.iter.org/ (accessed on 24 May 2021).

10. Taylor, N. Accident Analysis Report (AAR) Volume 1-Event Identification and Selection. IDM No. ITER_D_2DPVGT v1.4. Available online: https:/ / www.iter.org/ (accessed on 24 May 2021).

11. Cheng, X.; Ma, X.; Wang, W.; Chen, L.; Liu, S.; Xu, Y. Primary heat transfer system design of the WCCB blanket for multiple operation modes of CFETR. Fusion Eng. Des. 2020, 153, 111489. [CrossRef]

12. Cheng, X. Water-cooled blanket design. In Proceedings of the CFETR Engineering Design Annual Conference, Langfang, China, 26-29 October 2020. (In Chinese)

13. Mitteau, R.; Stangeby, P.; Lowry, C.; Merola, M.; The ITER Blanket Section. Heat loads and shape design of the ITER first wall. Fusion Eng. Des. 2010, 85, 2049-2053. [CrossRef]

14. Igitkhanov, Y.; Fetzer, R.; Bazylev, B. Effect of heat loads on the plasma facing components of demo. Fusion Eng. Des. 2016, 109-111, 768-772. [CrossRef]

15. Ilic, M.; Messemer, G.; Zinn, K.; Kiss, B. HETRA experiment for investigation of heat removal from the first wall of helium-cooledpebble-bed test blanket module. Fusion Eng. Des. 2011, 86, 2250-2253. [CrossRef]

16. Ilic, M.; Messemer, G.; Zinn, K.; Meyder, R.; Kecskés, S.; Kiss, B. Experimental and numerical investigation of heat transfer in the first wall of Helium-Cooled-Pebble-Bed Test Blanket Module-Part 1: Presentation of test section and 3D CFD model. Fusion Eng. Des. 2015, 90, 29-36. [CrossRef] 
17. Peng, J.; Huang, Y.; Xu, J.; Xiao, Z.; Duan, S. Method of the modeling and abstraction of typical thermal experiment unit for sub-critical fuel components. Nucl. Power Eng. 2015, 36, 9-13.

18. Kim, S.K.; Park, S.D.; Jin, H.G.; Lee, E.H.; Yoon, J.S.; Lee, D.W. Current status of Korea heat load test facility KoHLT-EB for fusion reactor materials. IEEE Trans. Plasma Sci. 2017, 45, 1820-1823. [CrossRef]

19. Lian, Q.; Tian, W.; Gao, X.; Qiu, S.; Su, G. Study of flow instability in parallel channel system for water cooled blanket. Fusion Eng. Des. 2019, 148, 111291. [CrossRef] 